\title{
Influence of canyon aspect ratio on microclimatic conditions: case of Lodz, Poland
}

\author{
Anna Bochenek ${ }^{*}$, and Katarzyna Klemm \\ ${ }^{1}$ Institute of Environmental Engineering and Building Installations, Faculty of Civil Engineering, \\ Architecture and Environmental Engineering, Lodz University of Technology, Lodz, Poland
}

\begin{abstract}
This study presents an analysis of the effect of height/width proportions of street canyons on microclimatic conditions in the most urbanized part of Lodz. The empirical research covered public spaces located in the so-called Greater City Zone of Lodz, which were included in the revitalization process. In this case, two street canyons were selected, which are used as pedestrian and driving canyons (the so-called woonerfs). At first, the authors determined the average weather conditions prevailing in the warm period of Typical Meteorological Year in the area of city. On their basis, microclimatic parameters prevailing in the areas of selected street canyons were evaluated with the use of computer simulations. The next stage included the determination of aspect ratio (AR) defining the ratio of building height forming the frontage of canyons to the street width. Finally, the relation between the determined coefficient and selected weather parameters was studied.
\end{abstract}

\section{Introduction}

Public spaces are considered as core areas in the structure of cities. They perform service and communication functions, and are also the most important places where the inhabitants' social life takes place [1]. The microclimatic conditions prevailing there have a direct impact on the human energy balance and thus on the subjective assessment of thermal comfort. The time of staying in an external environment depends on them. Therefore, it is necessary to create citizen-friendly urban spaces in which appropriate microclimatic conditions will prevail.

\section{Area of revitalization transformations}

Poland is a country located in Central Europe. Lodz is the third largest city in terms of population numbers and fourth in terms of area. Long-term planning activities in Lodz have been focused on comprehensive transformations of the urban fabric and its surrounding as a part of the revitalization process. Records of strategic documents for the city pay special attention to undertake work in the historical parts of Lodz due to progressing adverse infrastructural and spatial changes. In accordance with the provisions of the Municipal

\footnotetext{
* Corresponding author: anna.bochenek@p.lodz.pl
} 
Revitalization Program for the city of Lodz 2026+, one of the strategic objectives has become the "revival of the area of residence" through the transformation of residential buildings with the fabric related to them functionally, i.e. public and semi-public spaces.

The study covered characteristic areas forming the structure of historical urban tissue street canyons (east-west and north-south woonerfs). Their selection was made on the basis of the provisions of planning documents that indicate selected spaces as priority areas. Furthermore, their orientation is considered to be typical. Most of the communication routes have east-west and north-south orientation in the city structure. Evaluation of the microclimatic conditions prevailing in their areas may contribute to the increase of the urban tissue standard along with the immediate neighbourhood, and thus to the increase in the intensity of the use of shared functions.

\subsection{Typical climatic conditions in Lodz}

Average meteorological conditions in a given area are reflected in the so-called Typical Meteorological Year. Depending on the method of its determination, it may be a combination of selected months of a multi-year period, which climatic parameters are considered to be the most representative, or an annual sequence of meteorological data of a selected calendar year, which has been considered the most typical in a multi-year period [2]. In accordance with the applicable European standard - PN-EN ISO 15927-4 - it is recommended to use at least 10 years of measurement sequences for its creation. Its selection is made by elimination of extreme and semi-extreme years. Therefore, it gives the possibility of describing the typical conditions prevailing in a given area [3]. The standard assumes the use of Typical Meteorological Year for special purposes. In the present case, it served to describe the average meteorological conditions prevailing in the areas of selected public spaces. Information was used as input data for the simulation of meteorological parameters.

The Typical Meteorological Year for Lodz was prepared on the basis of a sequence of 12-year data. Measurement and observation information was obtained from the database of the Institute of Meteorology and Water Management of the National Research Institute in Warsaw. In accordance with the standard, the following parameters were used for its creation: dry-bulb thermometer temperature, total solar radiation, relative humidity, as well as wind speed at an altitude of 10 meters above the ground surface. In this paper the Typical Meteorological Year was created by selecting the months of multi-year period, which deviation of the meteorological parameters values from their average values determined for multi-year period was the lowest.

The intensity of use of urban spaces is strongly related to the microclimatic conditions in their area. Literature studies have shown that the increase in physical activity of people in public spaces takes place in a warm period. This fact is confirmed by a study conducted by Huang et al. (2016) [4]. In order to assess the typical microclimatic conditions prevailing in the areas of selected street canyons, the authors determined the warm period of Typical Meteorological Year. In this case, the key parameter was air temperature. Based on average daily air temperature values, a median was determined for each calendar year.

Then the arithmetic mean of median was calculated, which enabled to determine the parameter value that is the transition point between warm and cold period of each year (subject to maintaining the temperature value above a threshold for minimum of 7 days). The conditions were defined as warm if the average daily air temperature value exceeded the median determined on the basis of parameter value throughout the year. If the assumption was met for individual days during the multi-year period, they were included in the warm period. On the basis of above procedure, a warm period was determined for the city from May 14th to September 24th. 


\subsection{Microclimatic simulations for selected street canyons}

Assessment of microclimatic conditions prevailing in the areas of selected street canyons was made based on the analysis of computer simulation results. They were carried out by the ENVI-met software, which is widely used in analyses of the impact of urban structures on microclimatic parameters, and thus thermal comfort for users of public spaces. This application enables to create three-dimensional, non-hydrostatic, microclimatic models. It allows to simulate substrate-vegetation-air dependency in a 24-hour cycle. Moreover, it takes into account air flow between building structures, heat exchange process of vertical and horizontal surfaces, turbulence, vegetation parameters and dispersion of contaminants [5-6].

Initially, three-dimensional models of street canyons were created. The east-west oriented canyon was made on the basis of a rectangular grid with dimensions of $60 \times 30 \mathrm{x}$ 30 units with a resolution of $4 \mathrm{~m} \times 4 \mathrm{~m} \times 1 \mathrm{~m}$. For the north-south oriented canyon the dimensions of the model were $60 \times 75 \times 30$ units with $4 \mathrm{~m} \times 4 \mathrm{~m} \times 1 \mathrm{~m}$ resolution. Then, the microclimatic parameters of the Typical Meteorological Year were used as inputs to the simulation process. The basic parameters were: temperature, air relative humidity, direction, wind speed, atmospheric pressure as well as dew point temperature. The simulations were carried out for the average conditions of the warm period of the Typical Meteorological Year in a 24-hour cycle.

\section{Microclimate of selected public spaces}

Computer simulations of microclimatic parameters were conducted for selected street canyons. The studies were carried out for the warm period of Typical Meteorological Year. It enabled the determination of typical conditions prevailing in the priority areas of the city - selected street canyons in the period of the most intense use of them by inhabitants. Differentiation of microclimatic parameters in street canyons has been presented in Figure 1.
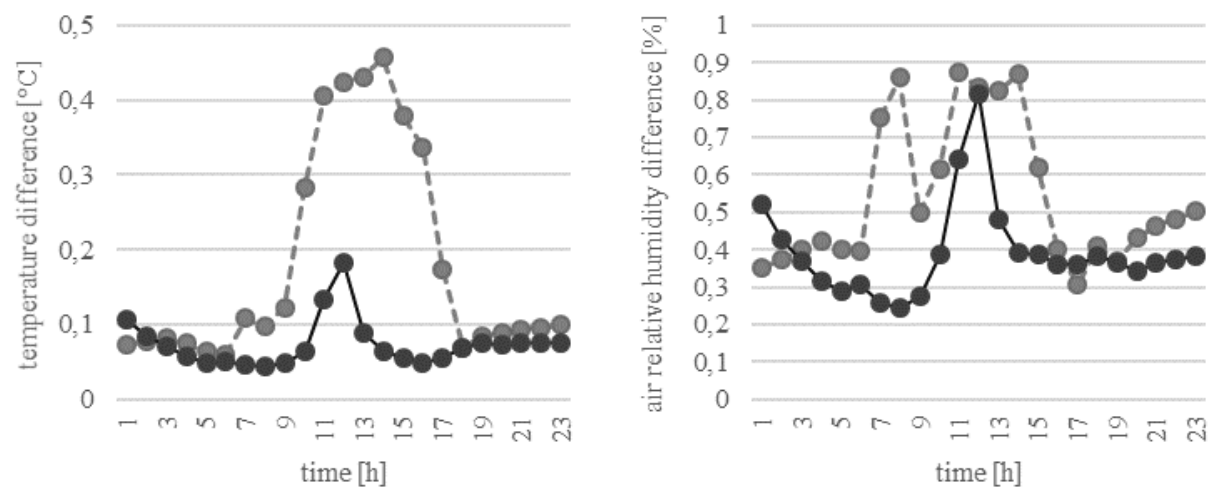

Fig. 1. The arithmetic mean of differences in meteorological parameters read at measurement points located at 2-meters distance from building fronts and 4-meter intervals along the main facades forming the frontage of street canyons (gray - the value difference between the measurement points located along north and south facade in east-west oriented canyon, black - the value difference between the measurement points along east and west facade in north-south oriented canyon). 
The parameter values (temperature and relative humidity) were read at points located at 2-meters distance from building fronts and 4-meter intervals along the main facades forming the frontage of street canyons (110 points in a north-south oriented canyon, 80 points in an east-west oriented canyon). Moreover, dependence of the above-mentioned on aspect ratio (AR) were evaluated. According to the literature AR is one of the most important parameters which influences the microclimate in public spaces [7-8].

The average air temperature ranged from $13.59^{\circ} \mathrm{C}$ to $20.67^{\circ} \mathrm{C}$ in the north-south orientation of the canyon. In the second case - east-west oriented canyon - it oscillated between $13.83-21.02^{\circ} \mathrm{C}$. The minima were recorded at 4.00 a.m. and the maxima at 2.00 p.m. Relative air humidity value ranged from $54.04 \%$ to $80.67 \%$ (north-south oriented canyon) and $53.25 \%$ to $79.49 \%$ (east-west oriented canyon).

The analysis of simulation results showed that a greater diversity of microclimatic parameters occurred in the area of the east-west street canyon. The average temperature difference was $0.54^{\circ} \mathrm{C}$, and the relative humidity $0.18 \%$. In the case of a north-south canyon, a temperature difference of $0.39^{\circ} \mathrm{C}$ and relative humidity of $0.07 \%$ was observed. The largest variation in parameters occurred between 10.00-17.00.
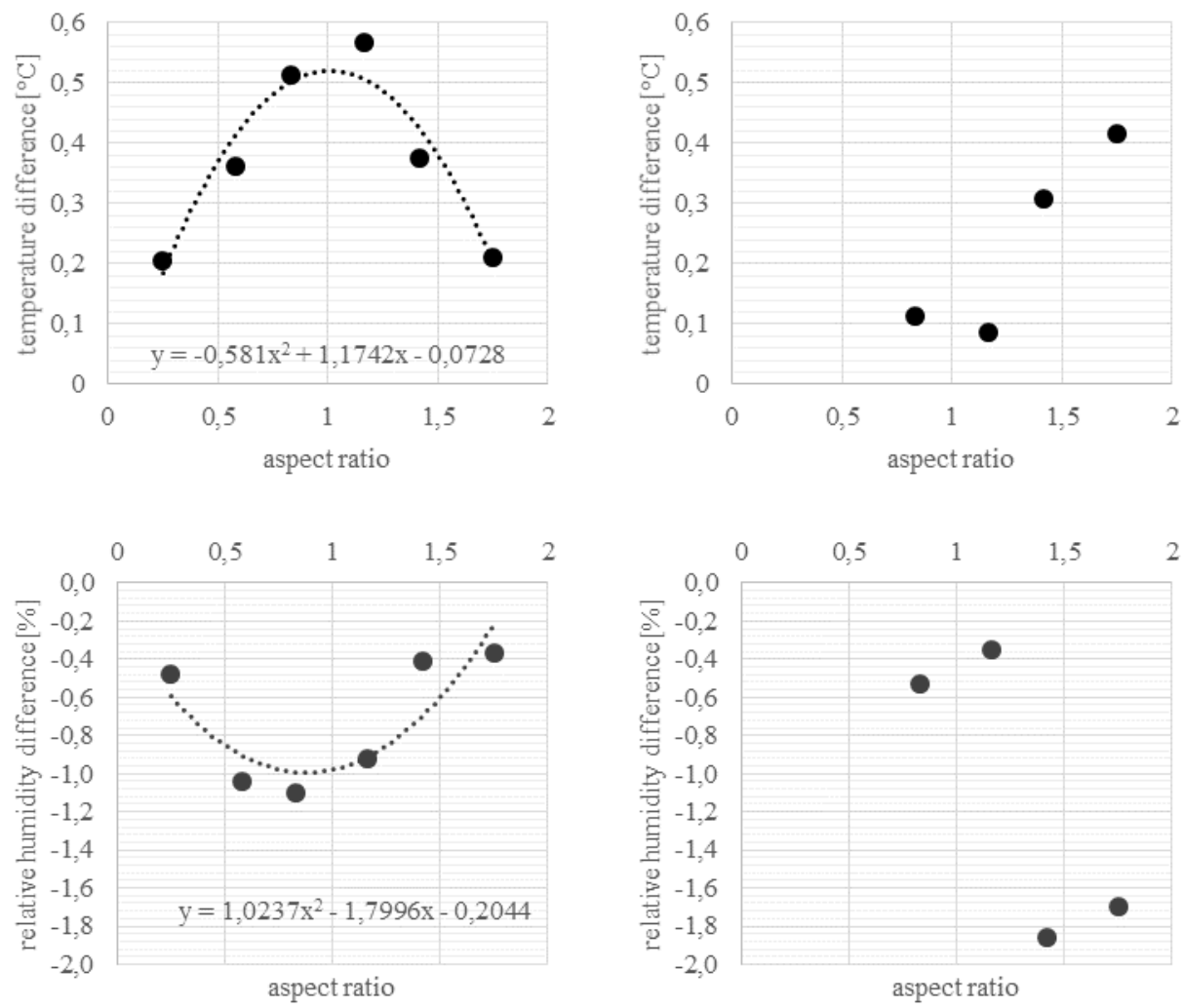

Fig. 2. Relation of AR coefficient and selected meteorological parameters (the canyon with east-west orientation - the left column; the canyon with north-south orientation - the right column).

Simulations showed a tendency to the occurrence of upper temperature extremes within the east-west traffic corridors. It should be assumed that it was related to strong heating of moving air masses as a result of heat transfer originally accumulated by artificial surfaces 
(low albedo). The most favorable temperature conditions were observed in the courtyards of tenement houses. This dependence was confirmed by Chatzidimitriou and Yannas. Material properties strongly modify microclimatic conditions. The lower the albedo of materials used in urban structures, the higher the air temperature [9].

Next, the coefficients of height ratio of frontage buildings to the width of street canyon were calculated. The arithmetic mean of air temperature difference on both sides of the canyon was determined for each element in the set (each and every value of aspect ratio). The dependence of AR coefficient and selected meteorological parameters is shown in Figure 2.

In case of an east-west oriented canyon, the obtained dependence was a second-degree curve with extremes $\mathrm{AR} \approx 1$. It should be assumed that with $\mathrm{AR}<1$ values, the height of buildings did not contribute to a significant decrease of air temperature along the southern facade of buildings. With AR $>1$, the influence of object geometry (shade cast by buildings) on the local microclimate could be observed. Then, the value of parameter decreased on both sides of the canyon. The dependence between AR and air humidity was reversed. Research conducted by Tumini et al., Martinelli and Matzarakis, De and Mukherjee confirmed the influence of building geometry on microclimatic parameters, and thus thermal comfort of users of public spaces. They showed that the higher the H/W ratio, the lower the air temperature. They also proved the positive impact of building height on the value of the thermal comfort indicator in the summer [7, 10-11].

These dependencies were not observed in the north-south orientation of a street canyon. In this case, the height of buildings had a negligible impact on the formation of climatic parameters. The location of objects did not reduce the amount of solar radiation reaching the earth's surface. Therefore, the surfaces absorbed heat relatively evenly throughout the canyon. Taleghani et al. confirmed the various influence of $\mathrm{H} / \mathrm{W}$ ratio on microclimatic parameters depending on the orientation of the canyon. Assessment of the impact of the urban form on the microclimate requires taking into account the local context, and thus conducting research for specific locations [12].

\section{Conclusions}

Empirical research has confirmed the validity of using representative conditions prevailing in a given area - the Typical Meteorological Year to simulate microclimatic parameters in street canyons. It gave the possibility of estimating typical conditions in selected, priority areas of the city. The analyses showed that the AR coefficient is a significant determinant in shaping the microclimate of east-west oriented traffic routes. In case of planning activities, it would be reasonable to determine the desired value of AR coefficient at which the temperature distribution reaches an acceptable level. Implementation of described strategy could contribute to the reduction of thermal discomfort in cities. For the northsouth oriented canyon no influence of AR coefficient on selected weather parameters was observed. In order to reduce thermal discomfort in north-south oriented canyon, another measures than modification of an urban form should be included.

This article is a prelude to the research on the influence of spatial development method on microclimatic conditions. Future studies should cover public spaces with different orientations. This would enable to assess the impact of street canyon geometry on the local microclimate and thus the thermal discomfort of their users. 


\section{References}

1. S. Thorsson, M. Lindqvist, S. Lindqvist, Int. J. Biometeorol., 48, 3, 149-156 (2004)

2. P. Narowski, District Heating, Heating, Ventilation, 45, 12, 479-485 (2014)

3. PN-EN ISO 15927-4, Hygrothermal performance of buildings. Calculation and presentation of climatic data. Part 4: Hourly data for assessing the annual energy use for heating and cooling (2007)

4. J. Huang, C. Zhou, Y. Zhuo, L. Xu, Y. Jiang, Build. Environ., 103, 238-249 (2016)

5. A. Middel, K. Häb, A. J. Brazel, C. A. Martin, S. Guhathakurta, Landscape Urban Plan., 122, 16-28 (2014)

6. Y. Wang, U. Berardi, H. Akbari, Procedia Engineer., 118, 137-144 (2015)

7. B. De, M. Mukherjee, Urban Climate, 24, 887-920 (2018)

8. L. Martinelli, A. Matzarakis, Sustain. Cities Soc., 29, 97-106 (2017)

9. A. Chatzidimitriou, S. Yannas, Energ. Buildings, 108, 156-174 (2015)

10. I. Tumini, E. H. Garcia, S. B. Rada, International Journal of Sustainable Building Technology and Urban Development, 7, 1, 22-37 (2016)

11. L. Martinelli, A. Matzarakis, Sustain. Cities Soc., 29, 97-106 (2017)

12. M. Taleghani, L. Kleerekoper, M. Tenpierik, A. Dobbelsteen, Build. Environ., 83, 6578 (2015) 